\title{
Diabetes in Elderly
}

\author{
Vishal Sharma ${ }^{\mathrm{a}}$, Sourabh Aggarwal ${ }^{\mathrm{b}, \mathrm{c}}$, Alka Sharma ${ }^{\mathrm{b}}$
}

\begin{abstract}
Diabetes is an important health issue across the globe. With increasing life expectancy physicians are called upon to manage diabetes in elderly more often. The review discusses issues in management of diabetes in geriatric patients.
\end{abstract}

Keywords: Diabetes; Geriatrics; Insulin

\section{Diabetes In Elderly}

The prevalence of Diabetes Mellitus increases with age [1]. Unfortunately, around half of these elderly diabetics go undetected in the west. This figure is likely to be more in the Indian subcontinent [2].

Therapeutic approach to Diabetes Mellitus in elderly should be different. Diabetes mellitus in elderly is metabolically distinct. Obese elderly have insulin resistance as a dominant metabolic abnormality while in lean elderly the problem is purely related to insulin secretion [3]. Elderly diabetics are more likely to have a normal hepatic glucose output and they also have a lower blood insulin level [4]. Presentation of diabetes in elderly is less classical. Index

Manuscript accepted for publication March 29, 2011

${ }^{a}$ Department of Gastroenterology, PGIMER, Chandigarh, India

${ }^{\mathrm{b}}$ Department of Medicine, University College of Medical Sciences, New Delhi, India

${ }^{\mathrm{c} C}$ Corresponding author: Sourabh Aggarwal, 257/6, Central Town,

Jalandhar City, Punjab - 144001, India.

Email: drsourabh79@gmail.com

doi:10.4021/jem11e of suspicion has to be high as patients usually do not develop glucosuria (increased renal threshold) and polydipsia (impaired thirst mechanism). They may present with nonspecific features (failure to thrive, falls, dizziness, confusion, nocturia, etc) and Non Ketotic Hyperosmolar State (NKHS) [5]. They may also present with infectious complications like malignant otitis externa, septicaemia, diabetic foot and complicated renal infections [5]. These situations may warrant insulin therapy. Postprandial hyperglycemia might be more important as PPBG has been found to be the best predictor of outcome in elderly.

\section{Problems in Managing Elderly Diabetics}

Elderly diabetics are usually on multiple drugs for multiple co-morbidities (e.g., hypertension, Coronary Artery Disease, dyslipidemia, etc) which lead to heightened concerns regarding compliance, side effects and drug interactions. Cognitive difficulties, higher incidence of depression, changed taste perception and abnormality in dentition in elderly may hamper appropriate adherence to the optimum treatment regimen [6]. Older people comply poorly with the drug recommendations. Co-morbidities make therapy challenging and therefore appropriate drug selection is needed.

\section{Oral Drugs in Elderly}

The use of oral drugs or insulin in elderly is associated with a higher risk of hypoglycemia. This could be due to reduced renal function, impaired counter regulatory mechanisms and hypoglycemia awareness.

Metformin is safe and effective in elderly diabetics. However it may cause lactic acidosis in patients with abnormal liver function or heart failure [7]. Thiazolidenediones are contraindicated in patients with heart failure and are associated with increased risk of fluid retention in the elderly [8]. Concurrent use of thiazolidenediones should be avoided. Sulfonylureas have a higher risk of hypoglycemia events due to reduced rates of elimination (especially with the long acting agents like glibenclamide and glyburide) [9]. Nateglinide 
Table 1. Goal of Therapy

\begin{tabular}{ll}
\hline American Geriatrics Association & Department of Veteran Affairs \\
\hline$<7 \%$ in adults with good functional status & $<7 \%$ if life expectancy is $>15$ years \\
$<8 \%$ if frail or life expectancy is $<5$ years & $<8 \%$ if life expectancy is $5-15$ years \\
& $<9 \%$ if life expectancy is $<5$ years \\
\hline
\end{tabular}

and repaglinide are associated with a lesser hypoglycemia risk and can be beneficial in elderly as they target postprandial hyperglycemia. Alpha-glucosidase inhibitors have a role in therapy of postprandial hyperglycemia and have been shown to reduce incidence of diabetes and macrovascular complications in elderly patients with impaired glucose tolerance and also increase insulin sensitivity [10].

\section{Insulin therapy in elderly}

Insulin therapy is safe in elderly provided it is accompanied by education and training of the patient to avoid any risk of hypoglycemia. It is important to clearly define the aims of therapy in an individual patient before initiation of insulin.

\section{Goals of Therapy}

While American Diabetics Association (ADA) recommends a HbA1C goal of $<7 \%$ [11], the American Diabetics Society and Department of Veteran Affairs have slightly different goals (Table 1).

It is appropriate not to use the intensive regimens in elderly patients with limited life expectancy, hypoglycemia unawareness, seizures, dementia, alcoholics, etc. This is because even minor hypoglycemia can result in cognitive defects, falls and injuries leading to long term functional decline [12-14].

\section{Principles of Insulin Treatment}

Insulin treatment should be started if oral anti-diabetics (OAD) prove inefficient and there is a lack of control with two OADS along with diet and exercise [15]. In renal and hepatic insufficiency (organ failure), the pharmacokinetics of the oral agent changes and therefore there is an increased risk of side effects limiting their use in such settings. Elderly diabetic patients are at an increased risk of developing severe and unusual infections like malignant otitis externa, urinary tract infections including life-threatening emphysematous pyelonephritis, rhinocerebral mucormycosis, and necrotizing fasciitis. In such situations insulin therapy is warranted to achieve optimum glycemic control. Elderly type 2 diabetic patients with dementia, infection, stroke, and myocardial infarction are predisposed to development of a state of severe

Table 2. Classification of Insulins Based on Their Duration of Action

\begin{tabular}{llll}
\hline Insulin & Onset & Peak & Duration \\
\hline Rapid & $5-15$ minutes & 30 minutes to 2 hours & $3-4$ hours \\
Lispro, Aspart, Glulisine & & & \\
Short & $30-60$ minutes & $2-3$ hours & $6-8$ hours \\
Regular & $2-4$ hours & $6-7$ hours & $10-20$ hours \\
Intermediate & & & 17 hours \\
NPH & 1 hour & Peakless & 24 hours \\
Long acting & $1-3$ hours & Peakless & \\
Detemir &
\end{tabular}


Table 3. Different Insulin Regimens

\section{Choice of regimen}

Single dose long acting insulin

Twice daily dose of long acting insulin

Premixed short/rapid acting and long

acting insulins (NPH and regular 70/30)

Basal bolus long acting with short/rapid acting (premeal)
Less than adequate control of sugars and a higher risk of hypoglycemia if used with OADs.

Better but often inadequate glycemic control.

Only two insulin injections needed.

Multiple insulin injections needed but with best control. Increased risk of hypoglycemia. dehydration (NKHS) secondary to osmotic diuresis resulting from hyperglycemia. It is characterised by high sugars and raised serum osmolality with fluid deficits in the range of 5 to 10 litres. Although fluid therapy is the mainstay for management, insulin therapy is indicated for the glycemic control. In acute medical emergencies like acute myocardial infarction, acute stroke and preoperative and postoperative euglycemia, Insulin remains the agent of choice.

\section{Considerations}

Various clinical and social situations must be taken into account before initiation of insulin therapy. Patients with altered visual acuity and manual dexterity are likely to have problems in appropriate adherence to therapy as also safe administration of insulin. Cognitive deficits again compromise the compliance with therapy as does pseudodementia associated with depression. In elderly diabetics it is usually appropriate to administer tests to determine the level of cognition using abbreviated mental test. In patients with an abnormal test, full MMSE is warranted. It is also prudent to assess the status of activities of daily living (ADL) using Barthel index and to rule out the presence of depression. This effort helps a long way in identifying a subset of elderly diabetics who may not be able to correctly administer the insulin or fail to identify and deal with hypoglycemia. Insulin therapy increases the cost of therapy compared with most OADs and the financial considerations must be factored prior to initiation of insulin therapy.

Ideal management should involve the patient. However the barriers mentioned above can prohibit self-management. These barriers can be overcome by providing the education and training in various aspects like SMBG and use of insulin

Table 4. Self-Monitoring of Blood Glucose (SMBG)

\begin{tabular}{lll}
\hline Clinical scenario & When to perform SMBG & Explanation \\
\hline Initiation of insulin & Premeal & To fix the dose of basal insulin \\
& Postprandial & $\begin{array}{l}\text { To fix the dose of rapid/short acting pre- } \\
\text { meal insulin }\end{array}$ \\
$\begin{array}{l}\text { After achieving pre-meal target insulin regimen } \\
\text { achieved }\end{array}$ & $\begin{array}{l}\text { Three point testing with judicious mix } \\
\text { of pre- and postprandial }\end{array}$ & $\begin{array}{l}\text { To recognize a failing regimen, an } \\
\text { asymptomatic hypoglycemia }\end{array}$ \\
$\begin{array}{l}\text { Unexplained hyperglycemia in } \\
\text { morning }\end{array}$ & 3 a.m. in the morning & To recognize somogyi phenomenon \\
\hline
\end{tabular}


administration devices [15]

\section{Insulin Preparations}

Insulins are classified on basis of their duration of action (Table 2) [16-18]. Short/rapid acting insulins are clear solutions of neutral $\mathrm{pH}$ and have a role in management of postprandial glucose excursions. Regular insulin is especially useful in the management of acute emergencies like NKHS and diabetic keto-acidosis (DKA). The rapid analogues have a useful benefit of limited duration of action irrespective of the dose as against regular insulin in which the duration of action is prolonged as the dose of insulin is increased. Also it is important to teach patients to take adequate early absorbable carbohydrate to avoid hypoglycemia after injections. The newer long acting insulin analogue, glargine is a clear solution with a peak less action [19]. It controls the fasting hyperglycemia better than bedtime NPH and is also associated with much lesser episodes of hypoglycemia. However the use of insulin analogue is associated with increased cost of management.

\section{How to Start}

An evening dose of NPH is usually used to start therapy [20]. Premixed insulin can help in improving compliance although risk of hypoglycemia is still there and also control of sugar is less easy with premixed insulin [21]. Although pre-meal short acting insulin analogues are likely to control the hypoglycemia (especially postprandial) better, such regimens are a bit too complex for elderly diabetics to comply with and need support from the family. Various insulin regimens are summarised in Table 3.

\section{How to Administer}

Studies in elderly have revealed that the formulations available in the pen form are preferable over the syringe as they are more safe and effective [22]. Conventional syringes, if used, should have bold markings. Pre-filled syringes may be of benefit in a sub group of elderly diabetics especially those with visual impairment because these do not need to be drawn up and mixed. Only recombinant human insulin is preferred now. Change of insulin species can affect glycemic control and should be done only under medical supervision. Insulin should be refrigerated and extremes of temperature should be avoided. Before every use, the insulin vial should be checked to look for changes like precipitation, change in colour or transparency. Rapid and short acting and glargine insulins are clear while others are cloudy.

Mixing may compromise efficacy as physiologic re- sponse to mixture of insulin is not the same as compared to the response to individual agent [23]. Lente should not be mixed with short acting insulin because ionic zinc in the lente binds to short acting insulin and delays its action. Mixing of NPH with rapid and short acting insulins is acceptable. However, mixing of NPH with lente can result in precipitation of phosphate buffer of NPH in form of zinc phosphate, thereby converting long acting preparation to a short acting one. Glargine is not to be mixed with any other insulin. While mixing short/rapid acting insulin with intermediate insulins, the clear short acting insulin should be drawn first. These injections should be given subcutaneously and the site of injection should be rotated to avoid any incidence of lipohypertrophy/lipoatrophy. Rapid acting insulin analogues must be injected 15 minutes prior to the meals while the regular insulins should be taken 30 minutes before the meals.

\section{Monitoring of Insulin Therapy}

Increasing use of self-monitoring of blood glucose (SMBG) has been found to correlate with a better glycemic control $[24,25]$. SMBG has a major role in guiding therapy in patients who are taking multiple daily doses of insulin. This would include virtually all the type 1 diabetics and also a subset of type 2 diabetics. SMBG also has a role in management of pregnant females on insulin as also patients on insulin pumps. The SMBG in various clinical settings can be done on the basis of Table 4. SMBG should be performed more frequently by patients with hypo/hyperglycemic symptoms, hypoglycemia unawareness, intercurrent illness, gastroparesis, etc.

\section{Conclusions}

It is important to realize that the treatment of other cardiovascular risk factors is of immense importance in patients of diabetes mellitus. In many of the elderly individuals the need for tight glycemic control is tempered by the presence of chronic conditions, physical and cognitive dysfunctions and also the presence of complications of diabetes. In such a scenario, less intense glycemic controls are more appropriate and should aim to avoid acute complications of hyperglycemia (dehydration, NKHS) as also the risk of hypoglycemia.

However the other cardiovascular risk factors should be appropriately managed in this subset. It is also warranted about the use of incretin mimetics. Exenatide, which is administered subcutaneously, and the oral dipeptidyl peptidase- 4 inhibitor sitagliptan act by stimulating the insulin secretion by a pathway unrelated to glucose [26]. Diabetes in elderly is associated with decrease in glucose mediated insulin secretion thereby raising the possibility of a possible role of these agents in the management of elderly diabetes. 
The overall goal is to formulate an acceptable treatment regimen to avoid symptoms and to preserve the quality of life.

\section{Conflicts of Interest}

None

\section{References}

1. Rowe JW. Health care of the elderly. N Engl J Med 1985;312(13):827-835.

2. Rao KVR, Seshaiah V. Epidemilogic features of noninsulin-dependent diabetes mellitus in the elderly in a developing country (India). Bulletin: Delivery of Health Care for Diabetics in Developing Countries 1987;8:2224.

3. Gumbiner B, Polonsky KS, Beltz WF, Wallace P, Brechtel G, Fink RI. Effects of aging on insulin secretion. Diabetes 1989;38(12):1549-1556.

4. Chen M, Bergman RN, Pacini G, Porte D, Jr. Pathogenesis of age-related glucose intolerance in man: insulin resistance and decreased beta-cell function. J Clin Endocrinol Metab 1985;60(1):13-20.

5. Gambert SR. Atypical presentation of diabetes mellitus in the elderly. Clin Geriatr Med 1990;6(4):721-729.

6. Lustman PJ, Clouse RE. Treatment of depression in diabetes: impact on mood and medical outcome. J Psychosom Res 2002;53(4):917-924.

7. Stang M, Wysowski DK, Butler-Jones D. Incidence of lactic acidosis in metformin users. Diabetes Care 1999;22(6):925-927.

8. Yki-Jarvinen H. Thiazolidinediones. N Engl J Med 2004;351(11):1106-1118.

9. Shorr RI, Ray WA, Daugherty JR, Griffin MR. Incidence and risk factors for serious hypoglycemia in older persons using insulin or sulfonylureas. Arch Intern Med 1997;157(15):1681-1686.

10. Meneilly GS, Ryan EA, Radziuk J, Lau DC, Yale JF, Morais J, Chiasson JL, et al. Effect of acarbose on insulin sensitivity in elderly patients with diabetes. Diabetes Care 2000;23(8):1162-1167.

11. Standards of medical care in diabetes--2010. Diabetes Care 2010;33 Suppl 1:S11-61.

12. Ott A, Stolk RP, van Harskamp F, Pols HA, Hofman A, Breteler MM. Diabetes mellitus and the risk of dementia: The Rotterdam Study. Neurology 1999;53(9):19371942.

13. Whitmer RA, Karter AJ, Yaffe K, Quesenberry CP, Jr., Selby JV. Hypoglycemic episodes and risk of dementia in older patients with type 2 diabetes mellitus. JAMA 2009;301(15):1565-1572.
14. Schwartz AV, Vittinghoff E, Sellmeyer DE, Feingold KR, de Rekeneire N, Strotmeyer ES, Shorr RI, et al. Diabetes-related complications, glycemic control, and falls in older adults. Diabetes Care 2008;31(3):391-396.

15. Brunton S, Carmichael B, Funnell M, Lorber D, Rakel R, Rubin R. Type 2 diabetes: the role of insulin. J Fam Pract 2005;54(5):445-452.

16. Binder C, Lauritzen T, Faber O, Pramming S. Insulin pharmacokinetics. Diabetes Care 1984;7(2):188-199.

17. Sindelka G, Heinemann L, Berger M, Frenck W, Chantelau E. Effect of insulin concentration, subcutaneous fat thickness and skin temperature on subcutaneous insulin absorption in healthy subjects. Diabetologia 1994;37(4):377-380.

18. Ratner RE, Hirsch IB, Neifing JL, Garg SK, Mecca TE, Wilson CA. Less hypoglycemia with insulin glargine in intensive insulin therapy for type 1 diabetes. U.S. Study Group of Insulin Glargine in Type 1 Diabetes. Diabetes Care 2000;23(5):639-643.

19. Riddle MC, Rosenstock J, Gerich J. The treat-to-target trial: randomized addition of glargine or human NPH insulin to oral therapy of type 2 diabetic patients. Diabetes Care 2003;26(11):3080-3086.

20. Nathan DM, Buse JB, Davidson MB, Heine RJ, Holman RR, Sherwin R, Zinman B. Management of hyperglycemia in type 2 diabetes: A consensus algorithm for the initiation and adjustment of therapy: a consensus statement from the American Diabetes Association and the European Association for the Study of Diabetes. Diabetes Care 2006;29(8):1963-1972.

21. Qayyum R, Bolen S, Maruthur N, Feldman L, Wilson LM, Marinopoulos SS, Ranasinghe P, et al. Systematic review: comparative effectiveness and safety of premixed insulin analogues in type 2 diabetes. Ann Intern Med 2008;149(8):549-559.

22. Lteif AN, Schwenk WF. Accuracy of pen injectors versus insulin syringes in children with type 1 diabetes. Diabetes Care 1999;22(1):137-140.

23. Insulin administration. Diabetes Care 2004;27 Suppl 1:S106-109.

24. Karter AJ, Ackerson LM, Darbinian JA, D'Agostino RB, Jr., Ferrara A, Liu J, Selby JV. Self-monitoring of blood glucose levels and glycemic control: the Northern California Kaiser Permanente Diabetes registry. Am J Med 2001;111(1):1-9.

25. Welschen LM, Bloemendal E, Nijpels G, Dekker JM, Heine RJ, Stalman WA, Bouter LM. Self-monitoring of blood glucose in patients with type 2 diabetes who are not using insulin: a systematic review. Diabetes Care 2005;28(6):1510-1517.

26. Demuth HU, McIntosh CH, Pederson RA. Type 2 diabetes--therapy with dipeptidyl peptidase IV inhibitors. Biochim Biophys Acta 2005;1751(1):33-44. 